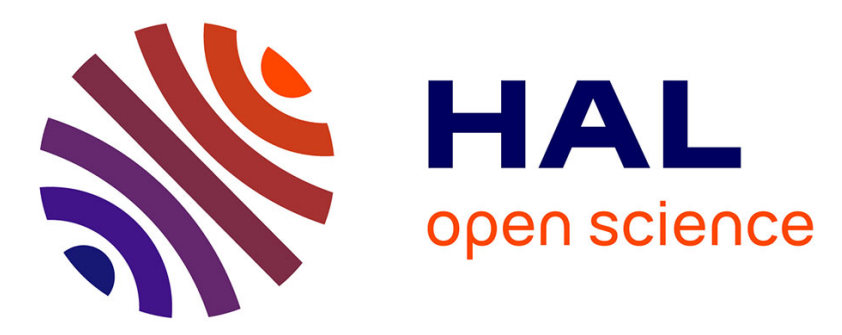

\title{
Induced Pluripotent Stem Cells for Primary Ciliary Dyskinesia Modeling and Personalized Medicine
} Joffrey Mianné, Engi Ahmed, Chloé Bourguignon, Mathieu Fieldes, Isabelle Vachier, Arnaud Bourdin, Said Assou, John de Vos

\section{To cite this version:}

Joffrey Mianné, Engi Ahmed, Chloé Bourguignon, Mathieu Fieldes, Isabelle Vachier, et al.. Induced Pluripotent Stem Cells for Primary Ciliary Dyskinesia Modeling and Personalized Medicine. American Journal of Respiratory Cell and Molecular Biology, 2018, 59 (6), pp.672-683. 10.1165/rcmb.20180213TR . hal-01878063

\section{HAL Id: hal-01878063 \\ https://hal.umontpellier.fr/hal-01878063}

Submitted on 20 Jan 2020

HAL is a multi-disciplinary open access archive for the deposit and dissemination of scientific research documents, whether they are published or not. The documents may come from teaching and research institutions in France or abroad, or from public or private research centers.
L'archive ouverte pluridisciplinaire HAL, est destinée au dépôt et à la diffusion de documents scientifiques de niveau recherche, publiés ou non, émanant des établissements d'enseignement et de recherche français ou étrangers, des laboratoires publics ou privés. 


\title{
Induced Pluripotent Stem Cells for Primary Ciliary Dyskinesia Modeling and Personalized Medicine
}

\author{
Joffrey Mianné ${ }^{1}$, Engi Ahmed ${ }^{1}$, Chloé Bourguignon ${ }^{1}$, Mathieu Fieldes ${ }^{1}$, Isabelle Vachier ${ }^{2}$, Arnaud Bourdin $^{2 \star}$, \\ Said Assou ${ }^{1 *}$, and John De Vos ${ }^{1,3 *}$ \\ ${ }^{1}$ Institute for Regenerative Medicine and Biotherapy, University of Montpellier, Institut National de la Santé et de la Recherche Médicale \\ (INSERM), Centre Hospitalier Universitaire Montpellier, Montpellier, France; ${ }^{2}$ PhyMedExp, University of Montpellier, INSERM, Centre \\ Hospitalier Universitaire Montpellier, Montpellier, France; and ${ }^{3}$ Centre Hospitalier Universitaire Montpellier, Department of Cell and Tissue \\ Engineering, Hospital Saint-Eloi, Montpellier, France
}

\begin{abstract}
Primary ciliary dyskinesia (PCD) is a rare and heterogeneous genetic disorder that affects the structure and function of motile cilia. In the airway epithelium, impaired ciliary motion results in reduced or absent mucociliary clearance that leads to the appearance of chronic airway infection, sinusitis, and bronchiectasis. Currently, there is no effective treatment for PCD, and research is limited by the lack of convenient models to study this disease and investigate innovative therapies. Furthermore, the high heterogeneity of PCD genotypes is
\end{abstract}

likely to hinder the development of a single therapy for all patients. The generation of patient-derived, induced pluripotent stem cells, and their differentiation into airway epithelium, as well as genome editing technologies, could represent major tools for in vitro PCD modeling and for developing personalized therapies. Here, we review PCD pathogenesis and then discuss how human induced pluripotent stem cells could be used to model this disease for the development of innovative, patient-specific biotherapies.

Keywords: PCD; iPSC; airway epithelium; cilia; therapy
Primary ciliary dyskinesia (PCD) is a rare, genetically heterogeneous lung disease. The disorder, first described by Siewert and Kartagener (1) as a combination of chronic sinusitis, bronchiectasis, and situs inversus (Kartagener's syndrome), was linked 40 years later to ciliary motility dysfunction (2). Since then, PCD-symptomatic features have been broadly studied and described, and great effort has been made to improve the diagnosis and characterization of the disease (3). In humans, motile cilia line the respiratory tract and provide the movement necessary for mucus transport. Due to impaired cilia motility and insufficient mucociliary clearance, patients with PCD present from infancy and throughout their life a variety of sinopulmonary symptoms, including chronic infections that cause sinusitis, rhinitis, and, eventually, bronchiectasis (3). As motile cilia are also important for the determination of the left-right asymmetry during embryogenesis, ciliary motion defects lead to situs inversus in approximately $50 \%$ of patients (3). PCD diagnosis can be delayed or missed, because most of the symptoms overlap with those of other pathologies, and no gold-standard diagnostic test is available (4).

Furthermore, there are only symptomatic treatments that are mostly based on transposition of what is used for patients with cystic fibrosis (CF) or with non-CF bronchiectasis (4). Importantly, despite the progress made in these past years to better characterize PCD, research on new therapeutics is limited. This could be mainly explained by the lack of convenient models to study the disease and test new therapies. The currently used model organisms do not exactly recapitulate the specificity of the human airway epithelium, and patient biopsies are useful, but are limited in quantity and only offer a short window of opportunities to perform experiments (5). Moreover, PCD is a rare disease with high clinical and genotypic heterogeneity. Different genes can be affected with a broad range of mutations, leading to a spectrum of phenotypes, from acute, life-threatening conditions to mild symptoms. This complexity is likely to be an obstacle to the development of a single therapy to treat all patients, and has probably led researchers to focus on more common and defined 
disorders to develop innovative therapies. Finally, PCD suffer from a lack of general public recognition compared with other rare genetic disorders, which results in fewer funding opportunities and less research.

Human induced pluripotent stem cells (hiPSCs) hold tremendous potential for disease modeling and cell therapy development. These cells, which are euploid, can self-renew indefinitely, differentiate into any cell type, and are amenable to genetic manipulation (6). Owing to these properties, several research teams have described the successful hiPSC differentiation into airway epithelium with multiciliated cells (7-11), opening the way to model respiratory diseases in a dish.

Here, after reviewing the structure of cilia and recapitulating the most recent knowledge about PCD, we discuss hiPSC potential for modeling this disease. We then explore different strategies that can be applied for the development of innovative, patient-specific biotherapies.

\section{Cilia and PCD}

\section{Ciliary Structure and Function}

Cilia are highly conserved organelles among eukaryotes and are present on most cell types in the human body. Their functions vary, depending on their structure and location. Nonmotile cilia are involved in sensory and signaling functions, and are generally present as a single appendage on most cell types. Motile cilia are mainly responsible for fluid movement and sperm motility, but can also have sensory functions (12). For instance, in the airway epithelium that lines the respiratory tract, motile cilia beat in a synchronized manner to generate the flow necessary for mucociliary clearance (13). Motile cilia are also localized on ependymal cells where they drive cerebrospinal fluid flow, and in the fallopian tubes for egg transport (14). Moreover, they are transiently present during embryogenesis as a solitary structure on the cells of the embryonic node, where they are involved in the determination of the left-right asymmetry pattern (1). Finally, the flagellum, a specialized motile cilium, governs spermatozoa motility (15).

During ciliogenesis, the axoneme emanates from the basal body docked to the apical cell membrane. This highly conserved structure is the most prominent part of the cilium, and consists of a cytoskeleton of microtubules and multiprotein complexes. In the axoneme, microtubules are arranged in a $9+2$ or $9+0$ pattern, where a ring of nine peripheral doublets surrounds, or does not surround, a central pair of singlet microtubules (16) (Figure 1).

In motile cilia, the ATP-dependent motor function is regulated by two distinct dynein complexes: the outer dynein arm (DA) and the inner DA. These two complexes generate the force necessary for the sliding of adjacent microtubule doublets relative to each other, which results in cilium bending through the regulation exercised by accessory axonemal components (17). These associated structures include the nexin-dynein regulatory complexes (N-DRCs) that link adjacent peripheral microtubule doublets, the central apparatus formed by a sheath of proteins surrounding the central pair, and the radial spokes that link the outer microtubule doublets to the central apparatus (16) (Figure 1). Axonemal subunits can be preassembled in the cytoplasm and are actively transported in and out of the cilium by the intraflagellar transport system. Moreover, all these axonemal structures show a highly conserved periodicity along the axoneme (18).

In conclusion, cilia are highly complex and regulated structures that involve hundreds of proteins. Therefore, deleterious mutations in any of the genes encoding proteins with a role in ciliogenesis, preassembly, axoneme structure, or ciliary transport can potentially lead to a ciliopathy, and to PCD when motile cilia are affected (19).

\section{PCD: Clinical Features and Diagnosis}

PCD clinical presentation is heterogeneous, and includes a broad range of symptoms that are commonly found in other
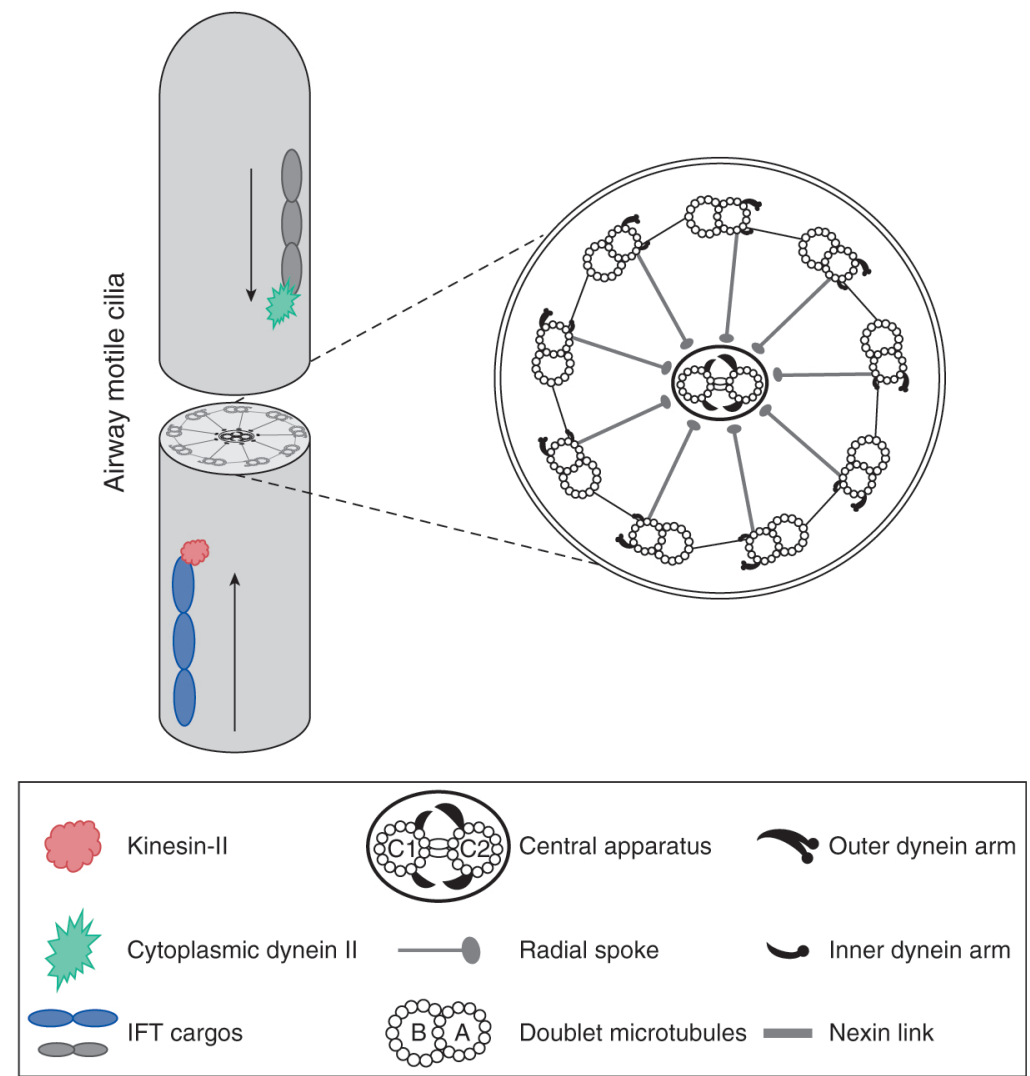

Figure 1. Structure of the axoneme of airway motile cilia. Schematic representation of the axoneme of airway epithelium motile cilia. Axonemal subunits are actively transported in and out of the cilium by the intraflagellar transport (IFT). IFT forms trains of axonemal subunit cargos that are delivered to the distal tip of the cilium for assembly and for protein turnover through the action of kinesin-II (anterograde transport). Recycling is mediated by the cytoplasmic dynein 2 motor that moves axonemal particles out of the cilium (retrograde transport). Axonemes are formed by microtubules and numerous multiprotein complexes repeated through the entire length of the structure. 
diseases. However, several combined and recurrent clinical features should evoke PCD. Specifically, from infancy and throughout their entire lives, patients with PCD report a variety of sinopulmonary symptoms with progressive decline of lung functions. These symptoms appear soon after birth, and neonatal respiratory distress is recorded in most cases (4). Most patients present persistent nasal congestion and recurrent cough, starting early during infancy and lasting through adulthood. Chronic infections of the upper and lower respiratory tract lead to sinusitis, rhinitis, and, eventually, bronchiectasis (4).

Recurrent acute otitis media also is common during childhood, leading to progressive hearing loss (3). Organ laterality defects are observed in half of the patients (Kartagener's syndrome) (4). Furthermore, dysfunction of ciliary motility in the fallopian tubes and of the sperm flagellum can lead to subfertility or infertility (20).

The prevalence of the disease is difficult to estimate, because PCD diagnosis can be delayed due to its nonspecific symptoms and absence of a screening test. Moreover, PCD is highly heterogeneous, with a broad range of possible mutations affecting many genes, and, despite the considerable progress made these past years, many other not-yetidentified genes could be associated with PCD. Thus, genetic testing remains expensive and time consuming without the certainty of a final diagnosis (21).

\section{PCD Genetics}

Recent advances in next-generation sequencing technologies have accelerated the discovery of PCD-associated genes. To date, 41 genes have been linked to PCD, among which 38 show an autosomal recessive inheritance pattern, and three are $X$ linked (RPGR, OFD1, and PIH1D3; Table 1). However, recent data suggest that PCD inheritance pattern and genetic cause might be more complex than thought, and could also be linked to transheterozygous mutations in PCDassociated genes (22). Most of the described PCD-associated gene variants are patient specific, with few recurring mutations. Usually, patients present compound heterozygous mutations with the exception of individuals with a history of consanguinity who harbor homozygous mutations.
PCD-associated genes encode proteins involved in various ciliary structures and functions, such as ciliogenesis, cytoplasmic preassembly of axonemal components, axonemal structure, and/or motility, that can lead to diverse ultrastructural defects and phenotypes (Table 1).

The mutation variability and the large number of genes that can be affected are likely to hinder the development of a single therapy for all patients with PCD. Therefore, the development of personalized treatments tailored to each individual patient will certainly be required for PCD management.

\section{PCD Modeling}

\section{Model Organisms}

To understand the molecular mechanisms underlying PCD, much research has focused on the study of cilia, and particularly the functions and structures associated with their motility. Despite their complexity, the architecture of cilia and flagellar axonemes are evolutionarily conserved among living organisms (23). This has allowed their study in many different model organisms, with specific advantages and limitations (Table 2). These models have also been essential for the identification of many PCD-associated genes and for the study of ciliopathies.

Pioneering studies were performed using the green alga, Chlamydomonas reinhardtii. In this biflagellate unicellular organism, the axonemal structure and protein composition of cilia show great similarity with human motile cilia (24). C. reinhardtii can be grown in large quantities, and mutants are readily obtained. Thanks to these features, this model has proven useful for characterizing the global protein composition of cilia, as well as for identifying genes and their roles in axonemal assembly, structure, and function. This has allowed the identification of homologous genes involved in PCD (25). Other unicellular organisms, such as Trypanosoma brucei and Tetrahymena thermophila, have been used to study cilia and to identify evolutionarily conserved structures of motile cilia/flagella. However, when compared with human motile cilia, these unicellular organisms show key differences in flagella structure and function that make impossible to fully recapitulate the specific ciliopathy phenotypes in such models.
Larger multicellular organisms, such as sea urchin, Caenorhabditis elegans, Xenopus laevis, Drosophila melanogaster, and Danio rerio, also have been used to study cilia biology and for PCD modeling. Investigations in the widely used $D$. rerio (zebrafish) model have allowed the identification and validation of PCD candidate genes and their function in ciliary motility. In this model, mutations in axonemal motility components can partially reproduce some of the effects seen in ciliopathies, including situs abnormalities. Nevertheless, all these models are phylogenetically distant from humans, and none of them fully recapitulate the pleiotropic symptoms observed in patients with PCD. Particularly, in these model organisms, cilia have unrelated functions with those of the multiciliated airway epithelium, thus limiting their use as PCD models. Indeed, the possibility of modeling the coordinated beating of cilia responsible for mucociliary clearance is a prerequisite for testing potential rescue therapies.

Therefore, various PCD mouse models have been generated. They show aspects of the disorder, such as ciliary dyskinesia, defective mucociliary clearance leading to rhinitis and sinusitis, situs abnormalities, and fertility defects (26). Mouse models can be used to investigate, at the whole-organism level, different aspects of PCD biology, and to test novel therapies. Nevertheless, as there are significant differences between human and mouse lungs (27), the phenotypes of many murine models are different from those of patients with PCD. For instance, severe hydrocephalus and cardiac defects associated with reduced viability are common outcomes in various mouse models, but not in patients with PCD. In addition, bronchiectasis, a hallmark symptom in patients with PCD, is not observed in these mice.

Overall, these model organisms are essential tools for deciphering cilia biology, but are less suitable for the development of novel PCD-therapeutic approaches (Table 2).

\section{Cell Culture Models}

PCD can be modeled in vitro using various protocols to obtain and maintain human airway epithelial cell (HAEC) cultures, and particularly 


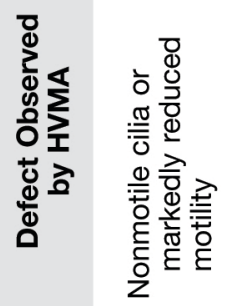

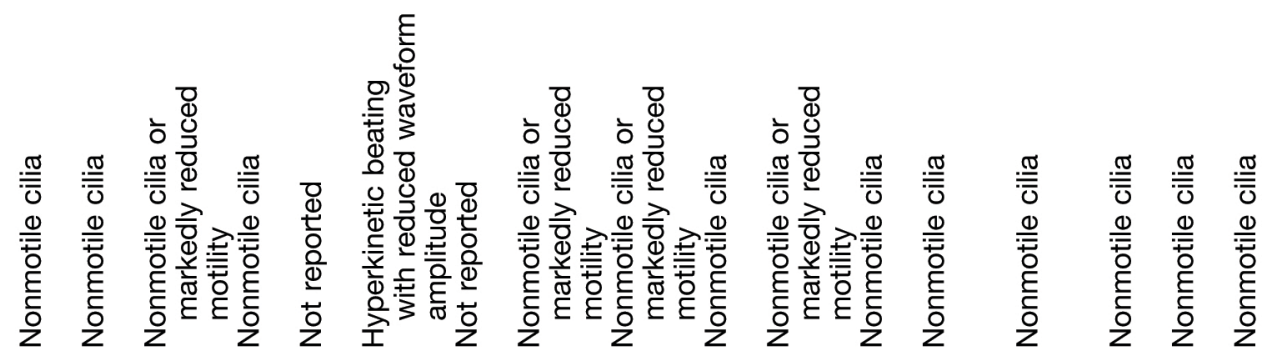

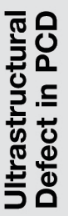

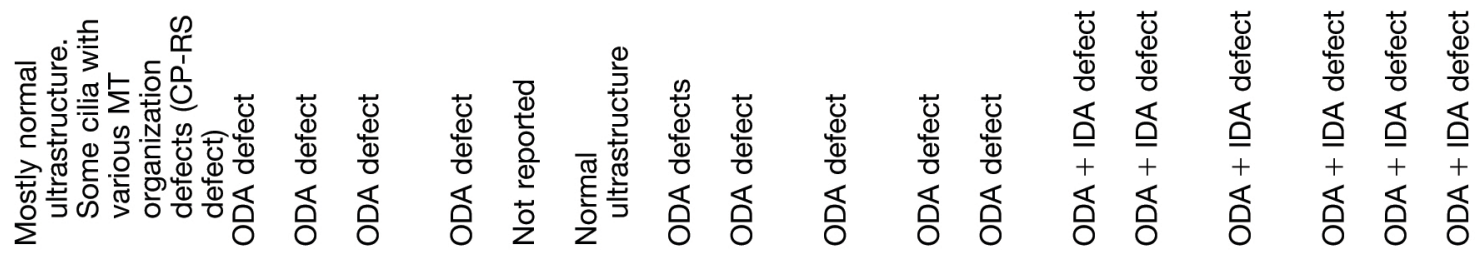

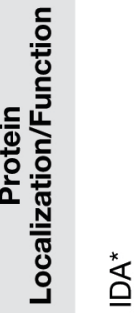

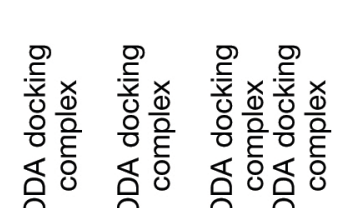
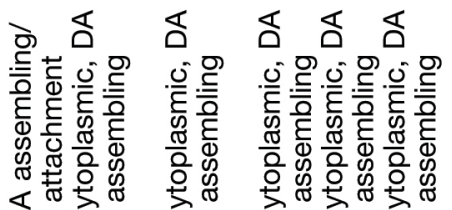

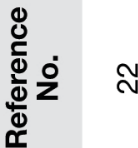

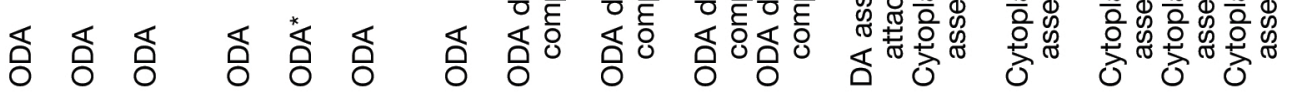

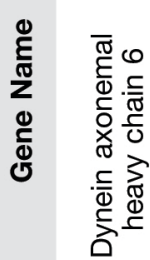
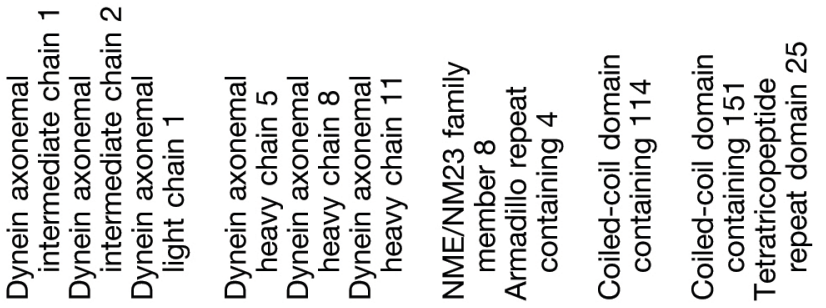

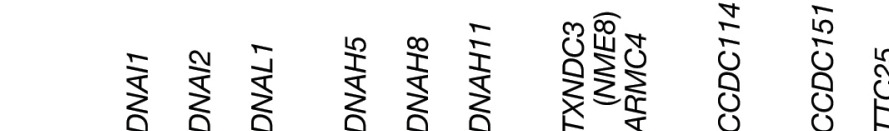

品

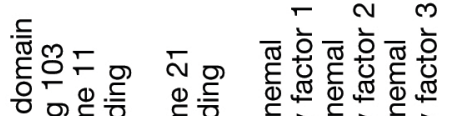

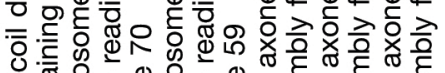

1.

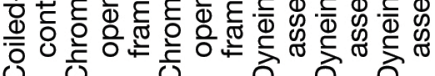




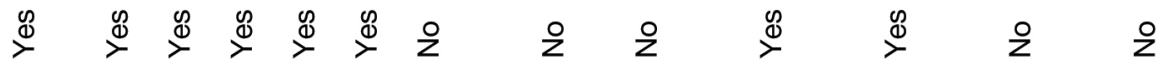

은

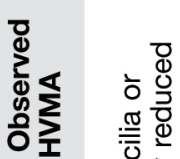

迹

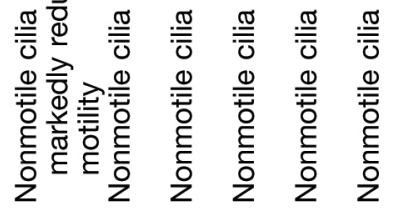

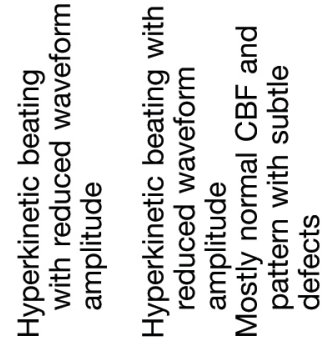

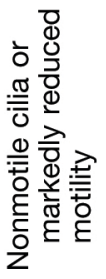

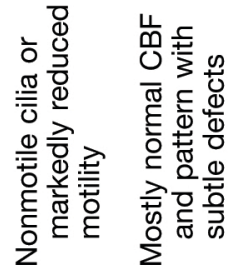

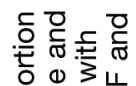

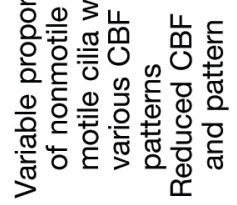

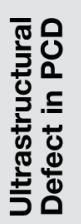

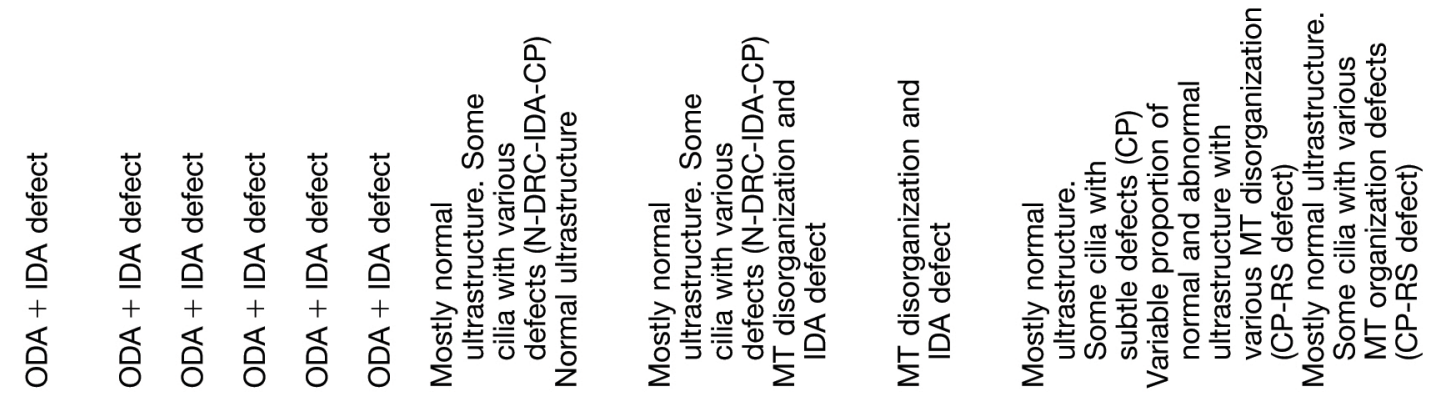

产

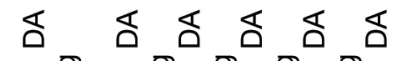

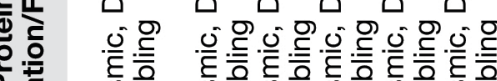

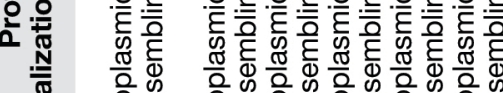

픙

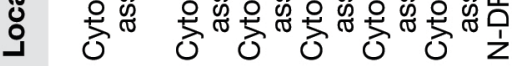

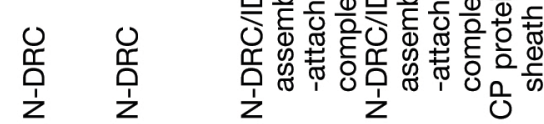

$\infty$
$\stackrel{0}{1}$
0
0

:

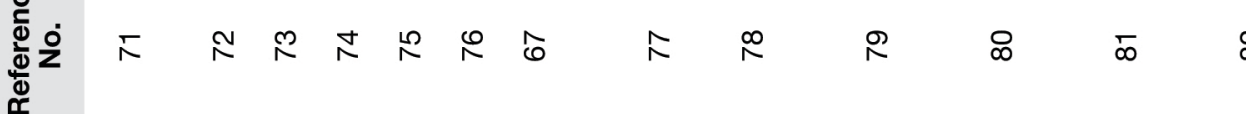

$\underset{\mathscr{C}}{\mathscr{2}}$

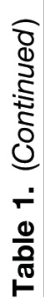

ֻั

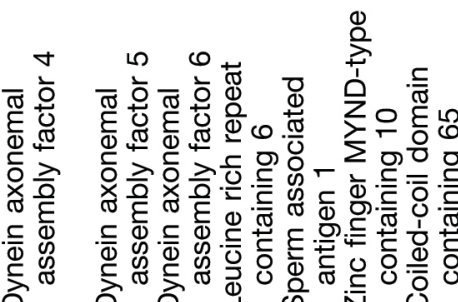

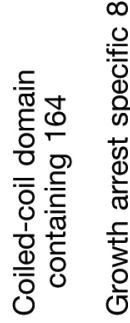

售

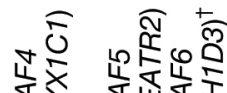

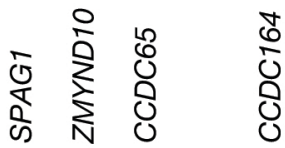

\begin{tabular}{lll}
\multirow{0}{0}{} & & गे \\
0 & $\infty$ & 0 \\
0 & 0 & 0 \\
0 & 0 & 0
\end{tabular}

요

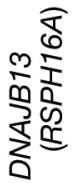




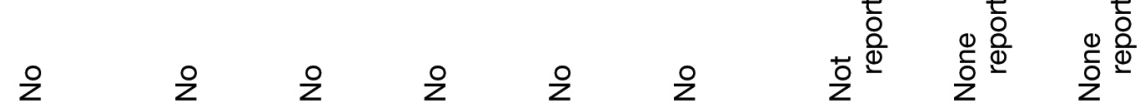

¿

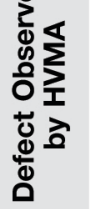

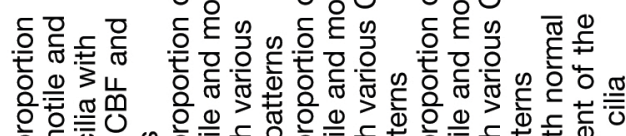

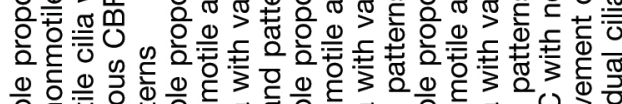

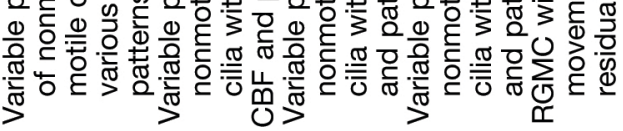

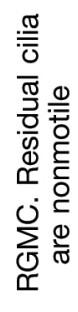

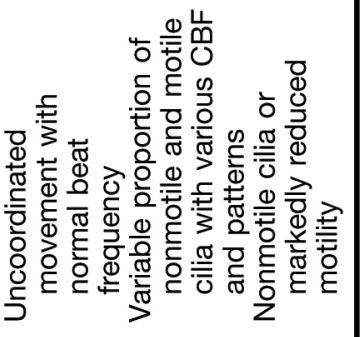

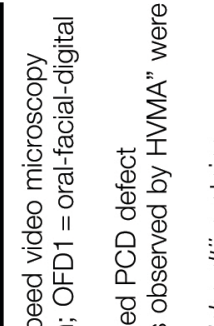

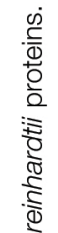

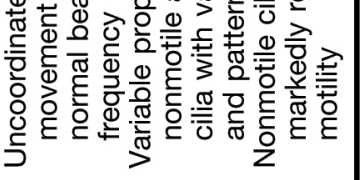

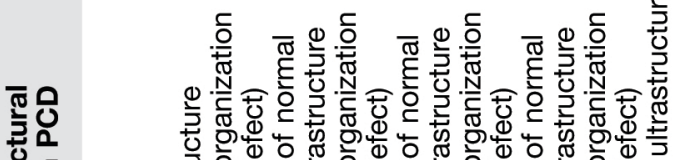

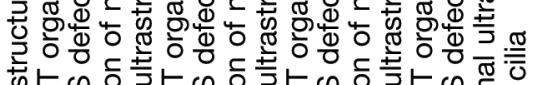

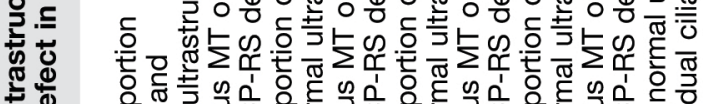

5ั

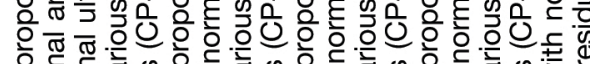

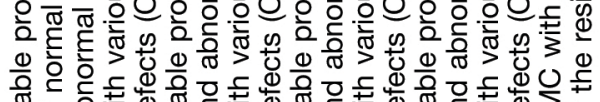

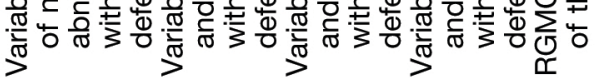

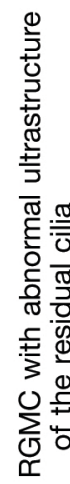

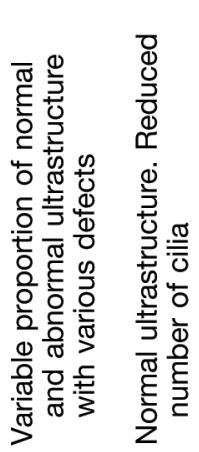

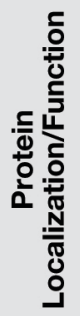

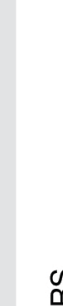

$\stackrel{8}{\circ}$

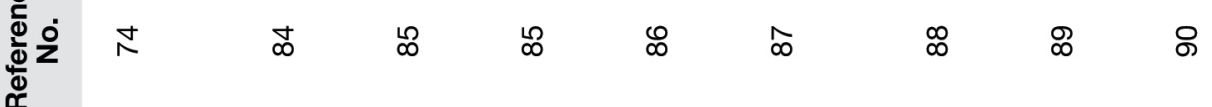

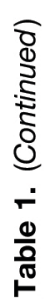

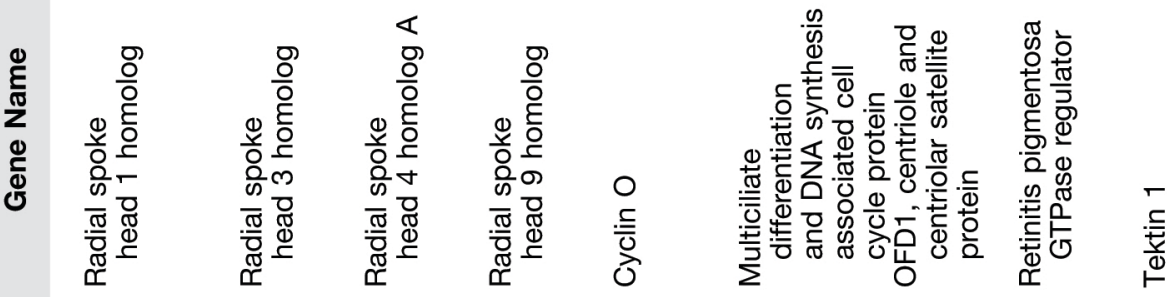

䱏

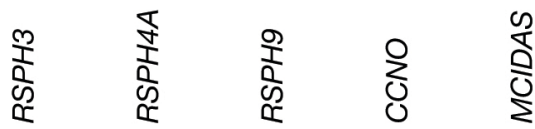

高喜薏

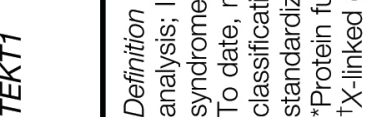


Model

Unicellular models (e.g., Chlamydomonas reinhardtii)

Multicellular organisms (e.g., Danio rerio)

\section{Mammal models}

(e.g., mouse)

HAEC lines

Primary HAECs

hiPSC-derived epithelium

Advantages

Disadvantages

Easy to culture/amplify

Mutants can be readily obtained

Phenotypically well characterized

Great models for basic research, candidate gene discovery, and validation

Easy to culture/amplify

Mutants can be readily obtained

Phenotypically well characterized

Great models for basic research, candidate gene discovery, and validation

Relatively easy to genetically manipulate

Cilia are highly similar in structure, protein composition, and functions

Recapitulate most of the PCD phenotypes

Great models for basic research and candidate gene validation

Good models to investigate potential PCD therapies at the whole-organism level

\author{
Easy to culture/amplify \\ Recapitulate most of the airway epithelia complexity \\ Good models for basic and applied research \\ Relatively good models to investigate potential PCD \\ therapies
}

\begin{abstract}
Recapitulate PCD genotype complexity/heterogeneity Recapitulate most of the airway epithelia complexity Good model for basic and applied research Good model to investigate potential PCD therapies

Recapitulate PCD genotype complexity/heterogeneity Recapitulate most of the airway epithelia complexity Unlimited amount of material Relatively easy to genetically manipulate

Great model for basic and applied research Great model to investigate potential PCD therapies
\end{abstract}

Differences in ciliary structure, protein composition, and functions compared with humans

Recapitulate only few PCD phenotypes

Poor models to investigate potential PCD therapies

Differences in ciliary structure, protein composition, and functions compared with humans

Recapitulate only some of the PCD phenotypes

Poor models to investigate potential PCD therapies

Differences between human and other mammal lungs

Do not fully recapitulate PCD pleiotropic phenotypes

Additional phenotypes can be observed

Difficulties to transpose results from therapeutic preclinical trials to humans

Genotypes, karyotypes, and phenotypes can differ from those of wild-type cells

Relatively difficult to genetically manipulate

Require invasive sampling methods

Difficult to culture and to amplify

High heterogeneity

Difficult to genetically manipulate

Differentiation protocols to be optimized for each cell line

Differentiation protocols remain time consuming and expensive

Genomic stability needs to be monitored

Definition of abbreviations: HAECs = human airway epithelial cells; hiPSC = human induced pluripotent stem cell; PCD = primary ciliary dyskinesia. List of the models that can be used to study PCD and investigate potential therapies. The advantages and disadvantages of each model are described to allow researchers to choose the best system for a specific question. iPSC-derived airway epithelium presents many advantages, making it an interesting platform to study PCD and evaluate personalized medicine.

multiciliated cells. Cultures can be performed using either cell lines (immortalized or engineered) or primary HAECs directly obtained from patient biopsies. Different culture conditions can be employed to induce differentiation of ciliated cells by growing cells in submersion, in an air-liquid interface (ALI), by allowing them to form $3 \mathrm{D}$ structures, or by using microfluidic systems, such as "airway-on-a-chip" (28).

The use of immortalized or engineered cell lines is convenient, because these cultures can be easily scaled up for multiple experiments. However, they are not genetically and physiologically entirely comparable with primary HAECs that give more realistic models, but have major limitations. Indeed, primary cells are obtained from donors using invasive techniques and have reduced dividing capacities when cultured in vitro, limiting the amount of available material. In addition, primary cells are patient specific, and might be sampled with pathogens, thus making them highly variable and not always viable for culture. Finally, it is still difficult to genetically manipulate primary cells.

Nevertheless, HAECs cultured in ALI and 3D systems present the major advantage of closely recapitulating the in vivo state, with the presence of specific cell types (progenitor basal cells, functional, multiciliated cells, mucus-producing goblet cells, and club cells) organized in a functional tissue. Moreover, recent progress in culture conditions has improved the in vitro expansion of HAECs and, consequently, the range of their applications (29-31).

Therefore, HAEC cultures are commonly used for the study of airway epithelium biology in physiological and pathological conditions, such as chronic obstructive pulmonary disease (32), asthma (32), CF (33), and PCD (34). Importantly, these in vitro models allow testing new 
therapies directly in the relevant human tissue.

\section{Differentiation of Human Induced Pluripotent Stem Cells into Proximal Airway Epithelium}

Differently from primary HAECs, hiPSC obtained from selected individuals offer the possibility to work with an unlimited source of cells that have a defined genotype and/or engineered mutations. Moreover, by inducing their differentiation into airway epithelium, hiPSC can be used as a model that could overcome the inherent limitations of HAEC cultures for developing and testing personalized PCD treatments.

The in vitro recapitulation of the successive steps of embryonic development (35) is the most straightforward strategy to develop a robust protocol for the differentiation of hiPSC into airway epithelium containing functional multiciliated cells. However, this has proved challenging, because knowledge on human embryonic lung development remains partial, and has been mainly transposed from mouse studies. Nevertheless, various protocols to differentiate pluripotent stem cells into multiciliated airway epithelium have been published (7-11). They result in the generation of functional, beating cilia characterized by the correct $9+2$ microtubule doublet arrangement with the associated DAs (10). It is worth noting that, although there is consensus about the key steps required for the direct differentiation of hiPSC into multiciliated airway epithelium, the protocols and yields described in the literature are quite heterogeneous (36). Here, we summarize the key consensual steps necessary to direct differentiation toward multiciliated airway epithelium.

Briefly, the first stage of differentiation includes the dual induction of transforming growth factor- $\beta$ and wingless-int1 (WNT) signaling by incubating hiPSC with high concentrations of activin- $A$ and low concentrations of CHIR99021 (a glycogen synthase kinase inhibitor that acts as a WNT pathway activator), respectively. This leads to the production of anterior primitive streak cells that can be further differentiated into definitive endoderm, characterized by the expression of the transcription factors, FOXA2 and SOX17, and the surface protein, CXCR4 (37). Then, the simultaneous inhibition of the BMP and transforming growth factor- $\beta$ signaling pathways with Noggin and the small molecule, SB431542, respectively, allows definitive endoderm differentiation into anterior foregut endoderm cells that express FOXA2 and SOX2. Activation of the WNT, BMP, and FGF signaling pathways will next induce lung lineage specification, as indicated by the generation of progenitor cells that express NKX2.1, the master regulator of lung development (38). The final differentiation into proximal airway epithelium progenitor cells that express NKX2.1 and SOX2 is initiated using ALI or $3 \mathrm{D}$ culture conditions and a cocktail of factors (FGF7, FGF10, BMP4, RA, and WNT3A) that includes Notch signaling inhibitors to promote ciliation $(9,10,39)$. This leads to the formation of a functional epithelium with basal cells, multiciliated cells, goblet cells, and club cells $(10,11)$. The identification of the fetal and adult lung epithelium gene expression program by single-cell mRNA sequencing (40), and advances in understanding human embryonic lung development (41), should help improve the protocols for in vitro differentiation of hiPSC into airway epithelium.

This is important, because the ability to efficiently differentiate hiPSC into airway epithelium allows the modeling of patientspecific conditions. This system can then be used as a multifunction platform to investigate the pathogenicity of suspected mutations, to study disease mechanisms, to perform highthroughput drug screens, and to evaluate the feasibility, efficacy, and safety of new therapies (Figure 2). Nonetheless, the use of hiPSC also comes with inherent constraints. Specifically, hiPSC can develop genetic abnormalities during prolonged cell culture. Therefore, hiPSC genome integrity must be routinely monitored to ensure the genotypephenotype correlation, and also to confirm their safety if used in therapy (42).

Moreover, the current protocols remain time consuming, and usually result in epithelia containing variable proportions of the different cell populations that can be significantly different from what is observed in normal bronchial epithelium. The precise stage of maturation also needs to be better studied, because hiPSC differentiation can result in cells blocked in a fetal-like state (43). Finally, reprogramming hiPSC comes with its own ethical considerations that should not be underestimated (44).

\section{Personalized Medicine}

To date, there is no effective therapy to manage PCD. Therefore, there is a great need to develop therapies to directly address the cause of the disease and rescue airway ciliary function. Moreover, due to PCD genetic and phenotypic heterogeneity, research should focus on developing specific strategies for each subset of patients with common features, or even individual patients.

To our knowledge, only four studies have evaluated approaches to restore the motility of airway cilia. Three of them used gene therapy approaches (45-47), whereas the last one assessed aminoglycosides to stimulate the readthrough of premature termination codons (48). These proof-ofconcept studies showed partial rescue of ciliary beating in vitro and in a mouse model, proving the feasibility and therapeutic potential of such approaches.

In this context, hiPSC differentiation to multiciliated airway epithelium represents a valuable in vitro model to investigate these personalized approaches to rescuing mucociliary clearance (Figure 2).

\section{Genome Engineering and Cell Therapies}

Gene and cell therapies, whereby the relevant cells are corrected in vivo or ex vivo, are among the most promising and attractive approaches to treat inherited genetic disorders, such as PCD.

Despite the limited research in the field of PCD, the development of therapies can benefit from the extensive work done over the past decades to develop efficient gene and cell therapies for other lung diseases, such as CF, alpha-1 antitrypsin, asthma, and cancer (49). These researches have highlighted the difficulties to genetically engineer a sufficient number of lung epithelial cells to correct the disease phenotype $(49,50)$. This is due to the presence of various physical and immunological barriers in the lung, as well as the difficulty in identifying stem cell populations in the bronchial epithelium. Currently, the development of lung cell or gene therapies is limited by two major obstacles: 1) it is still unclear which cell type is the most appropriate for gene engineering or cell therapy; and 2) the delivery of enough genetic material without inducing adverse effects remains a major bottleneck (50).

Two main gene therapy strategies are available to restore sufficient protein function. The first approach, which has been 


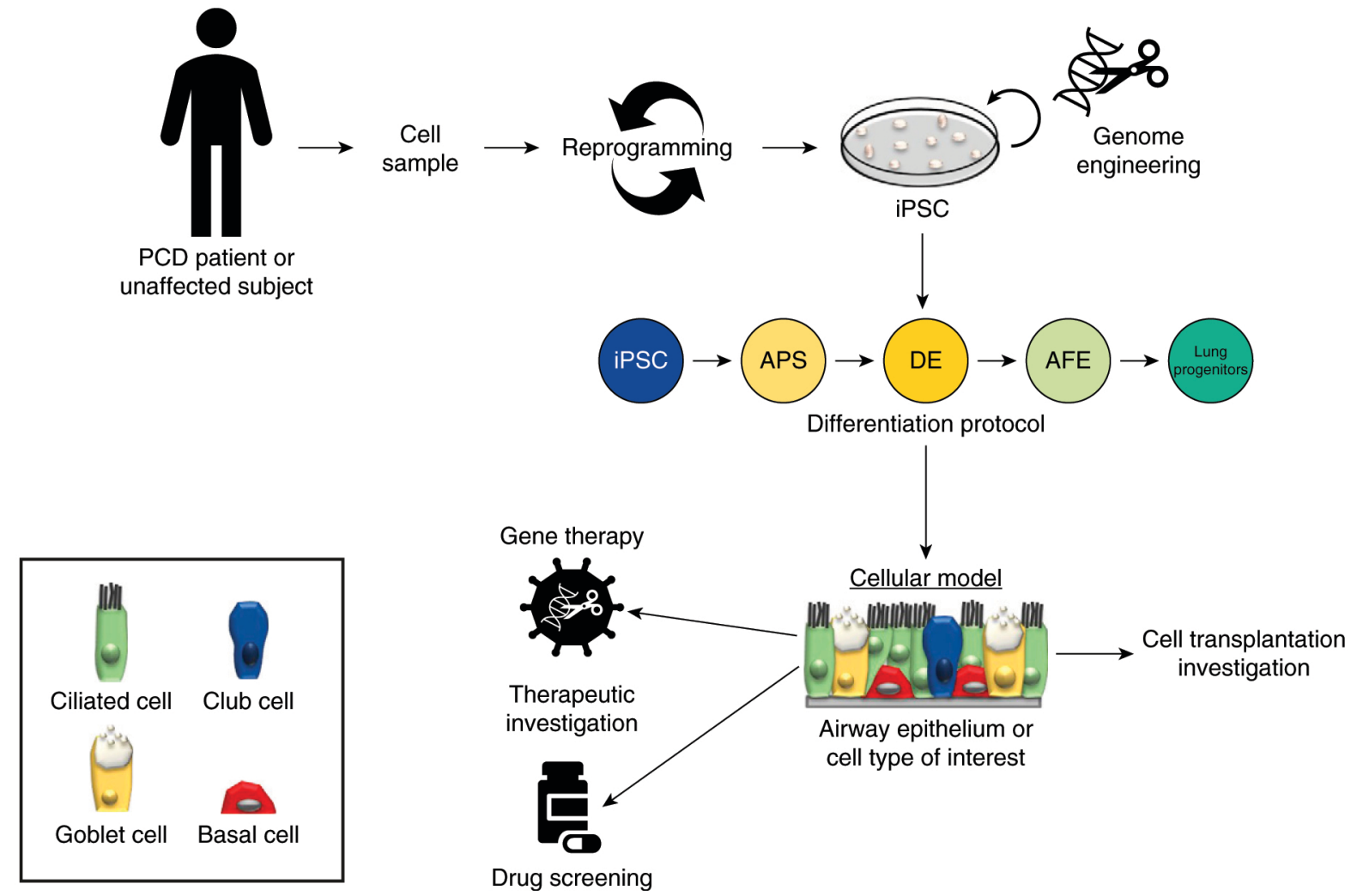

Figure 2. Potential pipeline to investigate personalized primary ciliary dyskinesia (PCD) therapeutics using airway epithelium-derived human induced pluripotent stem cells (hiPSCs). Schematic diagram describing a possible pipeline using patient-specific or genetically engineered hiPSCs and a differentiation protocol to generate an airway epithelium model of PCD. The obtained hiPSCs can be differentiated by providing stimuli that recapitulate in vitro the successive steps of embryonic lung development. Specifically, hiPSCs are first differentiated into anterior primitive streak (APS) cells to generate definitive endoderm (DE) cells. This is followed by DE differentiation into anterior foregut endoderm (AFE) cells to generate lung progenitor cells. Lung progenitors are finally differentiated into airway epithelium containing multiciliated cells by using appropriate culture conditions (air-liquid interface or three dimensional) and a cocktail of cytokines.

the strategy of choice in the past decades $(49,50)$, consists of inserting an exogenous transgene to provide a functional copy of the mutated gene. This approach is attractive, because it is not mutation specific, and a single design can be used for all patients with mutations in a given gene. The second approach relies on the specific engineering of the endogenous mutated alleles using gene editing technologies, such as the clustered regularly interspaced short palindromic repeats (CRISPR)/CRISPRassociated protein (Cas) system (51). These technologies, particularly the CRISPR/Cas9 approach, are still in their early days, but already show great promise for the efficient correction of pathogenic mutations.

The in vivo application of these different approaches requires the vectorization of the material used for the genetic manipulation. The community has acquired extensive experience using various vectorization systems for transgene delivery
(49), but the delivery of gene editing tools is still a work in progress. The available vectors include recombinant viral vectors derived from adenoviruses, adenoassociated viruses and lentiviruses, as well as nonviral vectors based on lipids, nanoparticles, and synthetic polymers (49). Each of these vectors has its specific advantages and disadvantages for gene delivery. Moreover, they need to be optimized for the appropriate cell model to overcome the many drawbacks that have emerged in previous clinical trials (49). In this context, developing an in vitro platform based on hiPSC differentiation into multiciliated airway epithelium might accelerate the development of new therapies by allowing scientists to investigate and optimize new strategies directly in the relevant tissue. Such a platform would enable the early assessment of the efficacy (i.e., number of corrected cells) and safety (i.e., specificity/genome- wide effect, effect on untargeted cells, inflammation, etc.) of personalized treatments before performing costly and timeconsuming in vivo experiments.

Ex vivo gene modification is also a promising strategy, because it provides optimal conditions for defect correction without the obstacles that hinder the in vivo approaches, such as the patient innate immune system response and the accessibility of distal airways. On the other hand, the debate is still open on the most suitable cell source(s) for ex vivo gene modifications: autologous versus allogeneic cells and differentiated hiPSC versus adult cells. Likewise, the cell population to be transplanted for long-term correction remains to be determined. Basal cells are progenitor cells, and a likely candidate for regenerative medicine, because they can self-renew and differentiate into more differentiated bronchial epithelium cells, including multiciliated cells (40). 
Nonetheless, further investigations are required to better characterize stem cell populations and to identify the most appropriate cell type(s) for such treatments. Finally, the mode of administration of the corrected cells is also a critical issue. However, the finding that fetal lung cells can be engrafted in the lung by intravenous infusion after progenitor ablation suggests that this difficulty may be overcome (52).

\section{Pharmacological Screens and Drug Discovery}

The ability to produce, at will, hiPSCderived airway epithelium with defined genotypes can also be exploited to perform drug screens at the patient level and in a high-throughput setting. Depending on the mutations found in each patient with PCD, different strategies could be studied to restore protein production and/or function, as already extensively done for CF (53). For nonsense mutations, which are common in patients with PCD, the propriety of molecules that allow the readthrough of premature termination codons, as described for aminoglycosides (54), could be investigated. Likewise, for specific mutations, screenings could be performed to identify small molecules, including antisense oligonucleotides, that can correct mis-splicing or compensate for the missing protein. For patients with hypomorphic mutations that allow the production of abnormal proteins with partial function, drug screening to find small molecules to compensate or restore the protein function could be envisaged.

\section{Conclusions}

PCD is a highly heterogeneous disorder primarily characterized by severe respiratory symptoms. Although PCD diagnosis and characterization have improved in recent years, the surge of interest seen in the clinic has yet to be translated to research laboratories. In fact, until now, only limited work has been done to develop innovative therapies for this disorder. This can in part be explained by the lack of reliable models to evaluate new approaches. In this review, we have described the potential of hiPSC-derived airway epithelium as a versatile platform to study PCD biology and investigate new therapeutics.

Genetically manipulated or patientderived hiPSCs are now routinely generated in laboratories, and can be used as an unlimited source of human cells. Their differentiation into airway epithelium is still under study, but its feasibility and efficacy have already been demonstrated. Such a model will allow working directly on the relevant tissue without the need for additional invasive procedures to be performed on the patients, and should facilitate the development of PCD treatments. Using this platform, researchers will have the possibility to recapitulate the genetic heterogeneity seen in patients with PCD, opening the way toward the development and testing of personalized biotherapies.

Therefore, this platform offers great opportunities to assess the feasibility, efficacy, and safety of a wide range of approaches, from gene therapy to ex vivo cell engineering for transplantation and drug screening. Given the advantages offered by hiPSC-derived airway epithelium, we anticipate that this model, in association with gene editing techniques, will become an essential platform for the development of new strategies for PCD management.

Acknowledgment: The authors thank E. Andermarcher (freelance editor) for critical reading of this manuscript.

\section{References}

1. Pennekamp P, Menchen T, Dworniczak B, Hamada $H$. Situs inversus and ciliary abnormalities: 20 years later, what is the connection? Cilia 2015;4:1.

2. Afzelius BA. A human syndrome caused by immotile cilia. Science 1976; 193:317-319.

3. Knowles MR, Daniels LA, Davis SD, Zariwala MA, Leigh MW. Primary ciliary dyskinesia. Recent advances in diagnostics, genetics, and characterization of clinical disease. Am J Respir Crit Care Med 2013; 188:913-922.

4. Knowles MR, Zariwala M, Leigh M. Primary ciliary dyskinesia. Clin Chest Med 2016;37:449-461.

5. Shoemark A. Models of ciliary dysfunction: time to expand [abstract]. Am J Respir Cell Mol Biol 2018;59:285-286.

6. Hockemeyer D, Jaenisch R. Induced pluripotent stem cells meet genome editing. Cell Stem Cell 2016;18:573-586.

7. Wong AP, Bear CE, Chin S, Pasceri P, Thompson TO, Huan LJ, et al. Directed differentiation of human pluripotent stem cells into mature airway epithelia expressing functional CFTR protein. Nat Biotechnol 2012;30:876-882.

8. McIntyre BAS, Alev C, Mechael R, Salci KR, Lee JB, Fiebig-Comyn $A$, et al. Expansive generation of functional airway epithelium from human embryonic stem cells. Stem Cells Trans/ Med 2014;3: 7-17.

9. Firth AL, Dargitz CT, Qualls SJ, Menon T, Wright R, Singer O, et al. Generation of multiciliated cells in functional airway epithelia from human induced pluripotent stem cells. Proc Natl Acad Sci USA 2014; 111:E1723-E1730.
10. Konishi S, Gotoh S, Tateishi K, Yamamoto Y, Korogi Y, Nagasaki T, et al. Directed induction of functional multi-ciliated cells in proximal airway epithelial spheroids from human pluripotent stem cells. Stem Cell Reports 2016;6:18-25.

11. McCauley KB, Hawkins F, Serra M, Thomas DC, Jacob A, Kotton DN. Efficient derivation of functional human airway epithelium from pluripotent stem cells via temporal regulation of Wnt signaling. Cell Stem Cell 2017;20:844-857.e6.

12. Shah AS, Ben-Shahar Y, Moninger TO, Kline JN, Welsh MJ. Motile cilia of human airway epithelia are chemosensory. Science 2009;325: 1131-1134.

13. Bustamante-Marin XM, Ostrowski LE. Cilia and mucociliary clearance. Cold Spring Harb Perspect Biol 2017;9:pii: a028241.

14. Choksi SP, Lauter G, Swoboda P, Roy S. Switching on cilia: transcriptional networks regulating ciliogenesis. Development 2014;141:1427-1441.

15. Linck RW, Chemes H, Albertini DF. The axoneme: the propulsive engine of spermatozoa and cilia and associated ciliopathies leading to infertility. J Assist Reprod Genet 2016;33:141-156.

16. Mizuno N, Taschner M, Engel BD, Lorentzen E. Structural studies of ciliary components. J Mol Biol 2012;422:163-180.

17. Ishikawa T. Axoneme structure from motile cilia. Cold Spring Harb Perspect Biol 2017;9:pii: a028076.

18. Burgoyne T, Dixon M, Luther P, Hogg C, Shoemark A. Generation of a three-dimensional ultrastructural model of human respiratory cilia. Am J Respir Cell Mol Biol 2012;47:800-806.

19. Fliegauf $M$, Benzing $T$, Omran $H$. When cilia go bad: cilia defects and ciliopathies. Nat Rev Mol Cell Biol 2007;8:880-893.

20. Vanaken GJ, Bassinet L, Boon M, Mani R, Honoré I, Papon JF, et al. Infertility in an adult cohort with primary ciliary dyskinesia: phenotypegene association. Eur Respir J 2017;50:1700314. 
21. Boaretto F, Snijders D, Salvoro C, Spalletta A, Mostacciuolo ML, Collura $\mathrm{M}$, et al. Diagnosis of primary ciliary dyskinesia by a targeted next-generation sequencing panel: molecular and clinical findings in Italian patients. $J$ Mol Diagn 2016;18:912-922.

22. Li Y, Yagi H, Onuoha EO, Damerla RR, Francis R, Furutani Y, et al. DNAH6 and its interactions with PCD genes in heterotaxy and primary ciliary dyskinesia. PLoS Genet 2016;12:e1005821.

23. Carvalho-Santos Z, Azimzadeh J, Pereira-Leal JB, Bettencourt-Dias M. Evolution: tracing the origins of centrioles, cilia, and flagella. $J$ Cell Biol 2011;194:165-175.

24. O'Toole ET, Giddings TH Jr, Porter ME, Ostrowski LE. Computerassisted image analysis of human cilia and Chlamydomonas flagella reveals both similarities and differences in axoneme structure. Cytoskeleton (Hoboken) 2012;69:577-590.

25. Pennarun G, Escudier E, Chapelin C, Bridoux A-M, Cacheux V, Roger $\mathrm{G}$, et al. Loss-of-function mutations in a human gene related to Chlamydomonas reinhardtii dynein IC78 result in primary ciliary dyskinesia. Am J Hum Genet 1999;65:1508-1519.

26. Mall MA. Role of cilia, mucus, and airway surface liquid in mucociliary dysfunction: lessons from mouse models. J Aerosol Med Pulm Drug Deliv 2008;21:13-24.

27. Fricker M, Deane A, Hansbro PM. Animal models of chronic obstructive pulmonary disease. Expert Opin Drug Discov 2014;9:629-645.

28. Hiemstra PS, Grootaers G, van der Does AM, Krul CAM, Kooter IM. Human lung epithelial cell cultures for analysis of inhaled toxicants: lessons learned and future directions. Toxicol In Vitro 2018;47: 137-146.

29. Butler CR, Hynds RE, Gowers KHC, Lee DdoH, Brown JM, Crowley C, et al. Rapid expansion of human epithelial stem cells suitable for airway tissue engineering. Am J Respir Crit Care Med 2016;194: 156-168.

30. Mou H, Vinarsky V, Tata PR, Brazauskas K, Choi SH, Crooke AK, et al. Dual SMAD signaling inhibition enables long-term expansion of diverse epithelial basal cells. Cell Stem Cell 2016;19:217-231.

31. Munye MM, Shoemark A, Hirst RA, Delhove JM, Sharp TV, McKay TR, et al. BMl-1 extends proliferative potential of human bronchial epithelial cells while retaining their mucociliary differentiation capacity. Am J Physiol Lung Cell Mol Physiol 2017;312:L258-L267.

32. Mertens TCJ, Karmouty-Quintana H, Taube C, Hiemstra PS. Use of airway epithelial cell culture to unravel the pathogenesis and study treatment in obstructive airway diseases. Pulm Pharmacol Ther 2017;45:101-113.

33. Bergougnoux A, Petit A, Knabe L, Bribes E, Chiron R, De Sario A, et al. The HDAC inhibitor SAHA does not rescue CFTR membrane expression in cystic fibrosis. Int J Biochem Cell Biol 2017;88:124-132.

34. Marthin JK, Stevens EM, Larsen LA, Christensen ST, Nielsen KG. Patient-specific three-dimensional explant spheroids derived from human nasal airway epithelium: a simple methodological approach for ex vivo studies of primary ciliary dyskinesia. Cilia 2017;6:3.

35. Dye BR, Miller AJ, Spence JR. How to grow a lung: applying principles of developmental biology to generate lung lineages from human pluripotent stem cells. Curr Pathobiol Rep 2016;4:47-57.

36. Gomperts BN. Induction of multiciliated cells from induced pluripotent stem cells. Proc Natl Acad Sci USA 2014;111:6120-6121.

37. Matsuno K, Mae SI, Okada C, Nakamura M, Watanabe A, Toyoda T, et al. Redefining definitive endoderm subtypes by robust induction of human induced pluripotent stem cells. Differentiation 2016;92:281-290.

38. Hawkins F, Kramer P, Jacob A, Driver I, Thomas DC, McCauley KB, et al. Prospective isolation of NKX2-1-expressing human lung progenitors derived from pluripotent stem cells. J Clin Invest 2017; 127:2277-2294.

39. Tsao P-N, Vasconcelos M, Izvolsky KI, Qian J, Lu J, Cardoso WV. Notch signaling controls the balance of ciliated and secretory cell fates in developing airways. Development 2009;136:2297-2307.

40. Montoro DT, Haber AL, Biton M, Vinarsky V, Lin B, Birket SE, et al. $A$ revised airway epithelial hierarchy includes CFTR-expressing ionocytes. Nature 2018;560:319-324.

41. Nikolić MZ, Caritg O, Jeng Q, Johnson JA, Sun D, Howell KJ, et al. Human embryonic lung epithelial tips are multipotent progenitors that can be expanded in vitro as long-term self-renewing organoids. eLife $2017 ; 6: 1-33$.
42. Assou S, Bouckenheimer J, De Vos J. Concise review: assessing the genome integrity of human induced pluripotent stem cells: what quality control metrics? Stem Cells 2018;36:814-821.

43. Huang SXL, Islam MN, O'Neill J, Hu Z, Yang Y-G, Chen Y-W, et al. Efficient generation of lung and airway epithelial cells from human pluripotent stem cells. Nat Biotechnol 2014;32:84-91.

44. Zheng YL. Some ethical concerns about human induced pluripotent stem cells. Sci Eng Ethics 2016;22:1277-1284.

45. Chhin B, Negre D, Merrot O, Pham J, Tourneur Y, Ressnikoff D, et al. Ciliary beating recovery in deficient human airway epithelial cells after lentivirus ex vivo gene therapy. PLoS Genet 2009;5:e1000422.

46. Ostrowski LE, Yin W, Patel M, Sechelski J, Rogers T, Burns K, et al. Restoring ciliary function to differentiated primary ciliary dyskinesia cells with a lentiviral vector. Gene Ther 2014;21:253-261.

47. Lai M, Pifferi M, Bush A, Piras M, Michelucci A, Di Cicco M, et al. Gene editing of DNAH11 restores normal cilia motility in primary ciliary dyskinesia. J Med Genet 2016;53:242-249.

48. Bukowy-Bieryllo Z, Dabrowski M, Witt M, Zietkiewicz E. Aminoglycoside-stimulated readthrough of premature termination codons in selected genes involved in primary ciliary dyskinesia. RNA Biol 2016;13:1041-1050.

49. Sondhi D, Stiles KM, De BP, Crystal RG. Genetic modification of the lung directed toward treatment of human disease. Hum Gene Ther 2017;28:3-84.

50. $\mathrm{Cao} \mathrm{H}$, Molday RS, Hu J. Gene therapy: light is finally in the tunnel. Protein Cell 2011;2:973-989.

51. Alapati D, Morrisey EE. Gene editing and genetic lung disease: basic research meets therapeutic application. Am J Respir Cell Mol Biol 2017;56:283-290.

52. Rosen C, Shezen E, Aronovich A, Klionsky YZ, Yaakov Y, Assayag M, et al. Preconditioning allows engraftment of mouse and human embryonic lung cells, enabling lung repair in mice. Nat Med 2015;21: 869-879.

53. Strug LJ, Stephenson AL, Panjwani N, Harris A. Recent advances in developing therapeutics for cystic fibrosis. Hum Mol Genet 2018;27: R173-R186.

54. Zingman LV, Park S, Olson TM, Alekseev AE, Terzic A. Aminoglycosideinduced translational read-through in disease: overcoming nonsense mutations by pharmacogenetic therapy. Clin Pharmacol Ther 2007; 81:99-103.

55. Loges NT, Olbrich H, Fenske L, Mussaffi H, Horvath J, Fliegauf M, et al. DNAI2 mutations cause primary ciliary dyskinesia with defects in the outer dynein arm. Am J Hum Genet 2008;83:547-558.

56. Mazor M, Alkrinawi S, Chalifa-Caspi V, Manor E, Sheffield VC, Aviram $M$, et al. Primary ciliary dyskinesia caused by homozygous mutation in DNAL1, encoding dynein light chain 1. Am J Hum Genet 2011;88: 599-607.

57. Olbrich H, Häffner K, Kispert A, Völkel A, Volz A, Sasmaz G, et al. Mutations in DNAH5 cause primary ciliary dyskinesia and randomization of left-right asymmetry. Nat Genet 2002;30:143-144.

58. Watson CM, Crinnion LA, Morgan JE, Harrison SM, Diggle CP, Adlard $\mathrm{J}$, et al. Robust diagnostic genetic testing using solution capture enrichment and a novel variant-filtering interface. Hum Mutat 2014; 35:434-441.

59. Schwabe GC, Hoffmann K, Loges NT, Birker D, Rossier C, de Santi $\mathrm{MM}$, et al. Primary ciliary dyskinesia associated with normal axoneme ultrastructure is caused by DNAH11 mutations. Hum Mutat 2008;29: 289-298.

60. Duriez B, Duquesnoy P, Escudier E, Bridoux A-M, Escalier D, Rayet I, et al. A common variant in combination with a nonsense mutation in a member of the thioredoxin family causes primary ciliary dyskinesia. Proc Natl Acad Sci USA 2007;104:3336-3341.

61. Hjeij R, Lindstrand A, Francis R, Zariwala MA, Liu X, Li Y, et al. ARMC4 mutations cause primary ciliary dyskinesia with randomization of left/right body asymmetry. Am J Hum Genet 2013;93:357-367.

62. Wu DH, Singaraja RR. Loss-of-function mutations in CCDC114 cause primary ciliary dyskinesia. Clin Genet 2013;83:526-527.

63. Hjeij R, Onoufriadis A, Watson CM, Slagle CE, Klena NT, Dougherty GW, et al.; UK10K Consortium. CCDC151 mutations cause primary ciliary dyskinesia by disruption of the outer dynein arm docking complex formation. Am J Hum Genet 2014;95:257-274. 
64. Wallmeier J, Shiratori H, Dougherty GW, Edelbusch C, Hjeij R, Loges NT, et al. TTC25 deficiency results in defects of the outer dynein arm docking machinery and primary ciliary dyskinesia with left-right body asymmetry randomization. Am J Hum Genet 2016;99:460-469.

65. Panizzi JR, Becker-Heck A, Castleman VH, Al-Mutairi DA, Liu Y, Loges NT, et al. CCDC103 mutations cause primary ciliary dyskinesia by disrupting assembly of ciliary dynein arms. Nat Genet 2012;44: 714-719.

66. Höben IM, Hjeij R, Olbrich H, Dougherty GW, Nöthe-Menchen T, Aprea I, et al. Mutations in C11orf70 cause primary ciliary dyskinesia with randomization of left/right body asymmetry due to defects of outer and inner dynein arms. Am J Hum Genet 2018;102:973-984.

67. Austin-Tse C, Halbritter J, Zariwala MA, Gilberti RM, Gee HY, Hellman $\mathrm{N}$, et al. Zebrafish ciliopathy screen plus human mutational analysis identifies $\mathrm{C} 21$ orf59 and CCDC65 defects as causing primary ciliary dyskinesia. Am J Hum Genet 2013;93:672-686.

68. Duquesnoy P, Escudier E, Vincensini L, Freshour J, Bridoux AM, Coste $A$, et al. Loss-of-function mutations in the human ortholog of Chlamydomonas reinhardtii ODA7 disrupt dynein arm assembly and cause primary ciliary dyskinesia. Am J Hum Genet 2009;85:890-896.

69. Omran H, Kobayashi D, Olbrich H, Tsukahara T, Loges NT, Hagiwara H, et al. Ktu/PF13 is required for cytoplasmic pre-assembly of axonemal dyneins. Nature 2008;456:611-616.

70. Mitchison HM, Schmidts M, Loges NT, Freshour J, Dritsoula A, Hirst $\mathrm{RA}$, et al. Mutations in axonemal dynein assembly factor DNAAF3 cause primary ciliary dyskinesia. Nat Genet 2012;44:381-389, S1-S2.

71. Tarkar A, Loges NT, Slagle CE, Francis R, Dougherty GW, Tamayo JV, et al.; UK10K. DYX1C1 is required for axonemal dynein assembly and ciliary motility. Nat Genet 2013;45:995-1003.

72. Horani A, Druley TE, Zariwala MA, Patel AC, Levinson BT, Van Arendonk LG, et al. Whole-exome capture and sequencing identifies HEATR2 mutation as a cause of primary ciliary dyskinesia. Am J Hum Genet 2012;91:685-693.

73. Olcese C, Patel MP, Shoemark A, Kiviluoto S, Legendre M, Williams HJ, et al.; UK10K Rare Group. X-linked primary ciliary dyskinesia due to mutations in the cytoplasmic axonemal dynein assembly factor PIH1D3. Nat Commun 2017;8:14279.

74. Kott E, Legendre M, Copin B, Papon JF, Dastot-Le Moal F, Montantin $\mathrm{G}$, et al. Loss-of-function mutations in RSPH1 cause primary ciliary dyskinesia with central-complex and radial-spoke defects. Am J Hum Genet 2013;93:561-570.

75. Knowles MR, Ostrowski LE, Loges NT, Hurd T, Leigh MW, Huang L, et al. Mutations in SPAG1 cause primary ciliary dyskinesia associated with defective outer and inner dynein arms. Am J Hum Genet 2013; 93:711-720.

76. Zariwala MA, Gee HY, Kurkowiak M, Al-Mutairi DA, Leigh MW, Hurd TW, et al. ZMYND10 is mutated in primary ciliary dyskinesia and interacts with LRRC6. Am J Hum Genet 2013;93:336-345.

77. Wirschell M, Olbrich H, Werner C, Tritschler D, Bower R, Sale WS, et al. The nexin-dynein regulatory complex subunit DRC1 is essential for motile cilia function in algae and humans. Nat Genet 2013;45: 262-268.
78. Olbrich H, Cremers C, Loges NT, Werner C, Nielsen KG, Marthin JK, et al. Loss-of-function GAS8 mutations cause primary ciliary dyskinesia and disrupt the nexin-dynein regulatory complex. Am J Hum Genet 2015;97:546-554.

79. Merveille AC, Davis EE, Becker-Heck A, Legendre M, Amirav I, Bataille $\mathrm{G}$, et al. CCDC39 is required for assembly of inner dynein arms and the dynein regulatory complex and for normal ciliary motility in humans and dogs. Nat Genet 2011;43:72-78.

80. Becker-Heck A, Zohn IE, Okabe N, Pollock A, Lenhart KB, SullivanBrown J, et al. The coiled-coil domain containing protein CCDC40 is essential for motile cilia function and left-right axis formation. Nat Genet 2011;43:79-84.

81. Olbrich H, Schmidts M, Werner C, Onoufriadis A, Loges NT, Raidt J, et al.; UK10K Consortium. Recessive HYDIN mutations cause primary ciliary dyskinesia without randomization of left-right body asymmetry. Am J Hum Genet 2012;91:672-684.

82. Edelbusch C, Cindrić S, Dougherty GW, Loges NT, Olbrich H, Rivlin J, et al. Mutation of serine/threonine protein kinase 36 (STK36) causes primary ciliary dyskinesia with a central pair defect. Hum Mutat 2017; 38:964-969.

83. El Khouri E, Thomas L, Jeanson L, Bequignon E, Vallette B, Duquesnoy $\mathrm{P}$, et al. Mutations in DNAJB13, encoding an HSP40 family member, cause primary ciliary dyskinesia and male infertility. Am J Hum Genet 2016;99:489-500.

84. Jeanson L, Copin B, Papon JF, Dastot-Le Moal F, Duquesnoy P, Montantin G, et al. RSPH3 mutations cause primary ciliary dyskinesia with central-complex defects and a near absence of radial spokes. Am J Hum Genet 2015;97:153-162.

85. Castleman VH, Romio L, Chodhari R, Hirst RA, de Castro SCP, Parker KA, et al. Mutations in radial spoke head protein genes $\mathrm{RSPH} 9$ and RSPH4A cause primary ciliary dyskinesia with centralmicrotubular-pair abnormalities. Am J Hum Genet 2009;84:197209.

86. Wallmeier J, Al-Mutairi DA, Chen C-T, Loges NT, Pennekamp P, Menchen T, et al. Mutations in CCNO result in congenital mucociliary clearance disorder with reduced generation of multiple motile cilia. Nat Genet 2014;46:646-651.

87. Boon M, Wallmeier J, Ma L, Loges NT, Jaspers M, Olbrich $\mathrm{H}$, et al. MCIDAS mutations result in a mucociliary clearance disorder with reduced generation of multiple motile cilia. Nat Commun 2014;5: 4418.

88. Budny B, Chen W, Omran H, Fliegauf M, Tzschach A, Wisniewska M, et al. A novel $X$-linked recessive mental retardation syndrome comprising macrocephaly and ciliary dysfunction is allelic to oralfacial-digital type I syndrome. Hum Genet 2006;120:171-178.

89. Moore A, Escudier E, Roger G, Tamalet A, Pelosse B, Marlin S, et al. RPGR is mutated in patients with a complex $X$ linked phenotype combining primary ciliary dyskinesia and retinitis pigmentosa. J Med Genet 2006; 43:326-333.

90. Ryan R, Failler M, Reilly ML, Garfa-Traore M, Delous M, Filhol E, et al. Functional characterization of tektin-1 in motile cilia and evidence for TEKT1 as a new candidate gene for motile ciliopathies. Hum Mol Genet 2018;27:266-282. 